\title{
- Mastite dos bovinos: histórico de suas formas clínicas
}

\section{- History of mastitis clinical classification}

\author{
* Lilian Gregory ${ }^{1}$ - CRMV-SP-p n 6698 \\ Eduardo Harry Birgel ${ }^{2}$ - CRMV-SP - $n^{0} 0018$ \\ MartinaHoedemaker ${ }^{3}$ \\ Eberhard Grunert ${ }^{\dagger}$
}

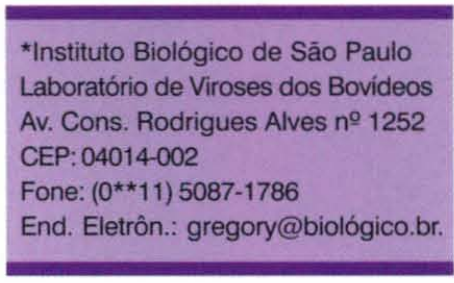

Instituto Biológico de São Paulo - Laboratório de Viroses dos Bovídeos/SP.

2 Professor Titular do Departamento de Clínica Médica Universidade de São Paulo - FMVZ/USP/SP.

3 Clínica de Ginecologia e Obstetrícia Escola Superior de Veterinária de Hannover/Alemanha.

"in memorian".

\section{RESUMO}

Na presente revisão estudou-se a evolução histórica da mastite dos bovinos e sua classificação em diferentes formas clínicas. O levantamento das informações só foi possível por meio de um estudo retrospectivo na biblioteca da Escola Superior de Veterinária de Hannover, onde se conseguiu dados do século XVIII até hoje.

Palavras-chave: mastite, clínica médica veterinária, bovinos.

\section{A} o final do século XVIII, considerava-se que as enfermidades da glândula mamária dos bovinos eram causadas por picadas de alguns insetos ou pelo contato com sangue ou com secreções de feridas supuradas. Também atribuía-se, nessa época, como uma das causas determinantes das moléstias que acometiam a glândula mamária, a influência de ocorrências fantasmagóricas ou maus espíritos; por essa razão, os assim denominados "mal do espírito" eram tratados e curados com "relíquias, água benta ou desinfetantes naturais".

Com Von WILLBURG, iniciaram-se, em 1787, estudos com bases científicas das doenças da mama, todavia, o empenho dos especialistas estava voltado apenas para a nosologia das moléstias da glândula mamária, não abordando aspectos relacionados à etiopatogenia dessas enfermidades, já que, naquela época, desconhecia-se a existência dos microrganismos. No manual que organizou e publicou, para orientação dos fazendeiros, o mencionado autor descreveu diferentes tipos de mastites, definindo-as como variadas formas de inflamações da glândula mamária. Em seguida, na evolução do tempo, originou-se um período que se caracterizaria pela observação das lesões e apreciação dos órgãos acometidos; assim, iniciaram-se as pesquisas e os estudos para o conhecimento da natureza intrínseca dos males que poderiam acometer a glândula mamária, que prejudicando a produção leiteira e alterando a qualidade do leite e dos produtos lácteos.

O interesse demonstrado por veterinários e criadores de gado leiteiro determinou o início de uma nova era no estudo da patologia da glândula mamária, pela necessidade prática e científica das classificações das mastites. RYCHNER (1835) classificou as mastites em: ativas, passivas e reumáticas. Porém, HAUBNER (1867) classificou-as em outras diferentes formas clínicas, ou 
GREGORY, L.; BIRGEL, E. H.; HOEDEMAKER, M.; GRUNERT, E. Mastite dos bovinos: histórico de suas formas clínicas / History of mastitis clinical classification / Rev. educ. contin. CRMV-SP / Continuous Education Journal CRMV-SP, São Paulo, volume 4, fascículo 3, p. 31 - 38, 2001.

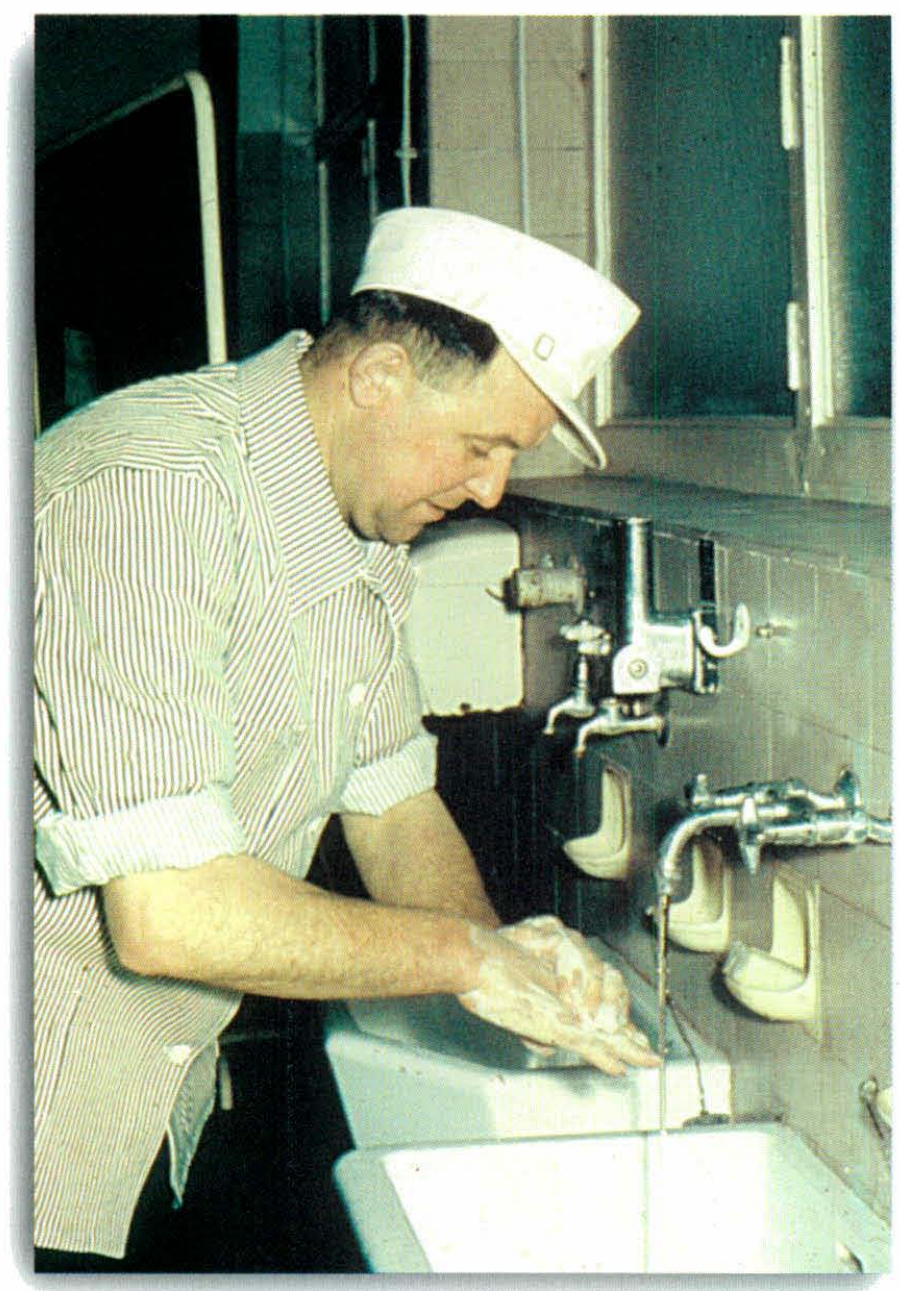

Figura 1. Vestuário apropriado e higienização das mãos antes da ordenha.

seja: a mastite superficial, a profunda, a parenquimatosa e uma forma grave de mastite.

No ano de 1876, Von FRANCK foi pioneiro em pesquisas relativas à etiologia infecciosa das mastites, mas, apesar de ter demonstrado a existência de microrganismos em amostras de leite, colhido de glândulas enfermas, não determinou quais seriam esses agentes etiológicos. Ressalte-se que isso se tornara possível a partir de 1676, graças à descoberta da microscopia óptica, por Antoni van Leevenhoek. Em seguida, ESCHERI$\mathrm{CH}$ (1885) descreveu germes coliformes como sendo um dos possíveis agentes causadores das mastites. NOCARD; MOLLEREAU (1885) evidenciaram germes, classificados como Streptococcus, em amostras de leite colhidas de quartos acometidos por mastite. Em 1908, KITT; GLAGE, em surtos de mastites em rebanhos leiteiros, determinaram que o agente etiológico das infecções mamárias era um microorganismo do gênero Streptococcus e propuseram dar-lhe o nome de Streptococcus agalactiae contagiosae, em substituição à designação Streptococcus nocardi. No ano de 1910,
POELS apresentou a primeira classificação etiológica das mastites baseada nos agentes etiológicos que as produziam: piobacilose; colibacilose e pseudocolibacilose; streptomicose; staphylomicose; pasteurelose; piocianose; necrobacilose; actinomicose e tuberculose.

Anteriormente, em 1908, KITT; GLAGE, avaliando a patogênese, os sinais e as alterações anatômicas e funcionais das mastites, classificaram-nas em duas formas: mastites infecciosas e não infecciosas. Na primeira forma clínica das mastites, a via de infecção poderia apresentar três possibilidades: hematogênica, quando o agente infeccioso alcançava o parênquima da glândula mamária pela corrente circulatória; galactogênica, quando o microorganismo tivesse como porta de entrada os "ductos papilares", ou seja, o canal do teto, e linfogênica, quando a penetração dos patógenos fosse pelos vasos linfáticos. Além do mais, o referido pesquisador, considerando o quadro sintomático, classificou essas enfermidades em: edema inflamatório, mastite catarral crônica e mastite tuberculosa crônica. Utilizando os critérios anatomopatológicos, KITT; GLAGE (1908) classificaram as formas clínicas de mastite em: edematosa do tipo infeccioso e não infeccioso; em catarral esporádica; em enzoótica catarral e, por último, em infecciosa purulenta esclerosante. HESS, em 1911, não adotou essa classificação e caracterizou a mastite como um processo infeccioso que poderia variar em suas manifestações quanto à intensidade dos sintomas e quanto à evolução da doença. Em obediência a esses princípios, ele dividiu a mastite em seis formas clínicas: mastite simples (com sintomas de pequena intensidade), mastite flegmonosa (forma caracterizada por sintomatologia grave), mastite recidivante, mastite metastática, mastite necrótica e mastite traumática (aquelas causadas pela penetração de corpos estranhos no tecido mamário).

GÖTZE (1931), pela primeira vez classificou as mastites obedecendo aos critérios propostos pela Propedêutica Veterinária, isto é, pelo exame do leite e pela avaliação criteriosa das características físicas da mama (volume, deformações, lesões e alterações da consistência, bem como da sensibilidade da mama). Assim sendo, pelas características da glândula e do leite, detectadas por inspeção, bem como pela avaliação por palpação dos tetos e dos seus tecidos constituintes, o mencionado pesquisador classificou as mastites, obedecendo a princípios e critérios clínicos, em três tipos: intersticial, catarral e parenquimatosa.

HEINDRICH; RENK (1963), seguindo a linha de raciocínio, preconizada por GÖTZE, fundador, em 1925, da Clínica de Bovinos da Escola Superior de Ve- 
terinária de Hannover, classificaram as mastites segundo as características clínicas e de evolução da doença, as qualidades físicas da secreção láctea, as alterações anatômicas e funcionais da glândula mamária e os resultados bacteriológicos do leite, caracterizando 8 formas clínicas de mastite, a saber: galactoforite e mastite catarral aguda; galactoforite e mastite catarral crônica, mastite aguda grave, mastite apostematosa crônica, mastite intersticial não purulenta, mastite tuberculosa, mastite actinomicótica e mastite blastomicótica. Observase que tal classificação não distinguiu claramente os critérios adotados, e os tipos resultantes, não foram detalhados de forma rigorosamente lógica, pois algumas formas caracterizavam-se pelos aspectos clínicos; outras, pela evolução da enfermidade, e, muitas, pela etiologia infecciosa.

SCHALM et al. (1971) classificaram as mastites segundo as suas formas clínicas em quatro tipos: hiperaguda; aguda; subaguda e subclínica. Todavia os critérios mencionados como básicos para a classificação não se referiam à forma clínica, mas ao tipo de evolução da doença. Na mastite hiperaguda distinguir-se-iam os seguintes sintomas: hiperemia, rubor, calor; dor, edema, alteração da função, além de o estado geral do animal estar alterado pela ocorrência da síndrome febre. Na mastite aguda os mesmos sinais de inflamação permaneciam evidentes, apesar de atenuados, podendo também observar-se febre e apatia do animal. Assim sendo, as duas formas de mastites não se diferiam pela sintomatologia, mas apenas pelo tempo de evolução. Quando, num caso de mastite hiperaguda ou aguda, desaparecessem os sinais evidentes do processo inflamatório, permanecendo apenas a perda de função, a mastite seria classificada como subaguda. Nos casos em que houvesse permanência do aumento da celularidade no leite, ocorreria uma mastite denominada como subclínica. Ressalte-se, entretanto, que, com essa última denominação, não poderia representar um dos itens de uma classificação de formas clínicas de uma doença. Além do mais, nos casos reais de infecção sempre existiriam sinais clínicos evidentes, que poderiam ser detectados no exame clínico, como: diminuição da produção leiteira, $\mathrm{pH}$ alcalino do leite, aumento dos teores de cloreto e do número de células somáticas, predominando polimorfonucleares neutrófilos.

WEIGT (1973) enfocou as mastites segundo as diferentes formas clínicas e, tendo em vista tal crité-

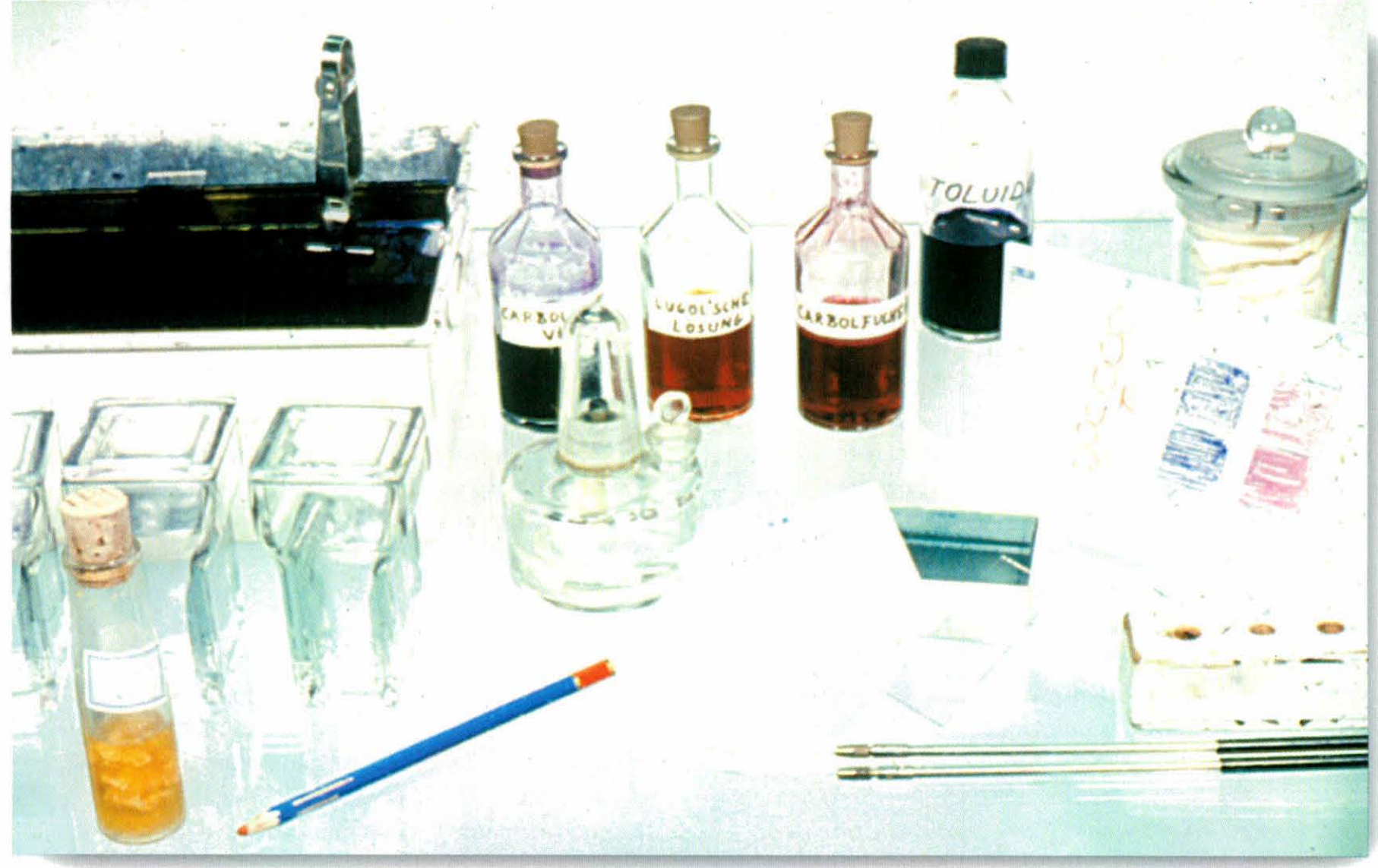

Figura 2. Material para a realização do exame do leite no laboratório. 


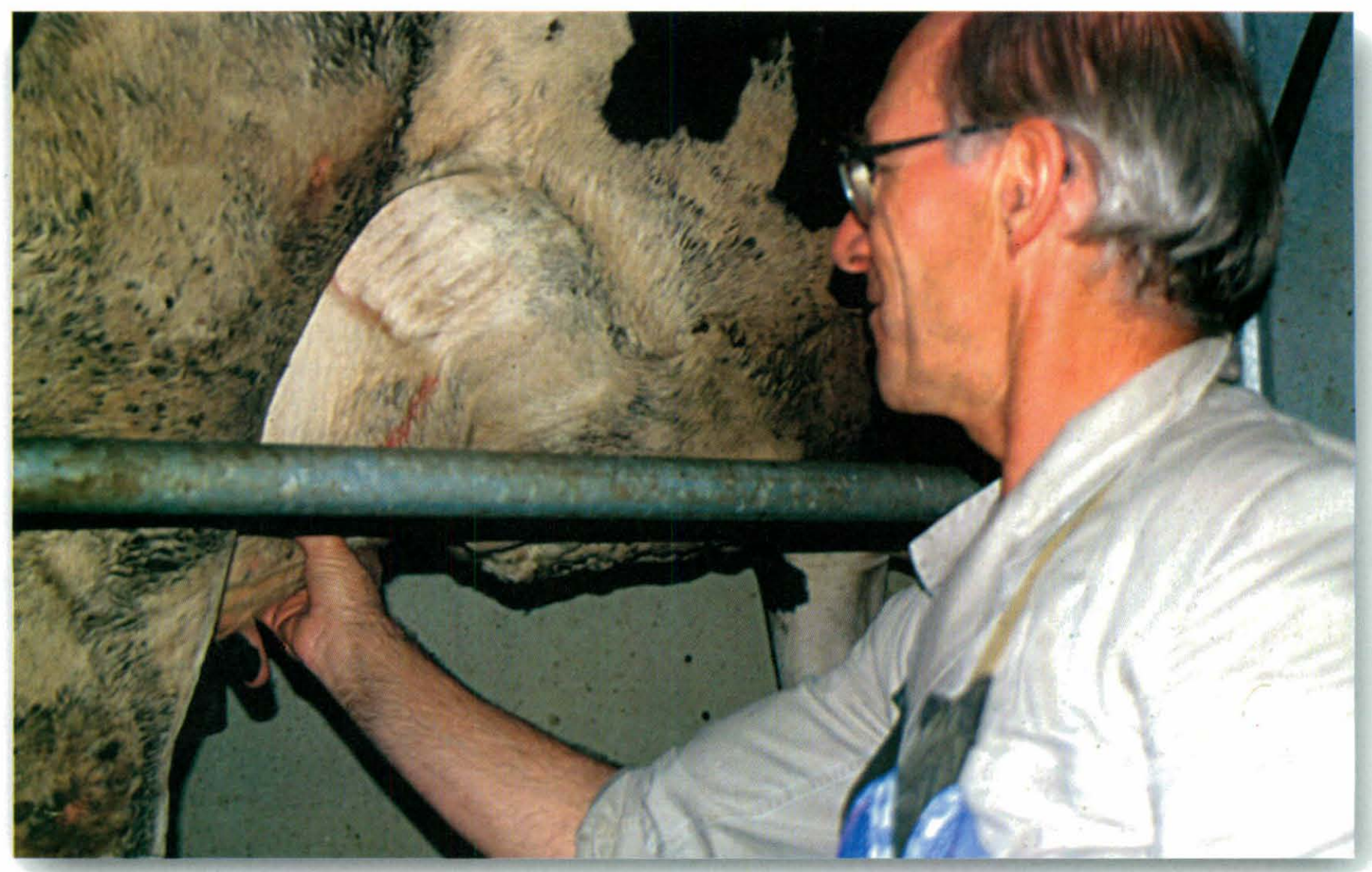

Figura 3. Exame clínico da glândula mamária: palpação.

rio, apontou as três formas mais comuns de mastites: a catarral, a apostematosa e a flegmonosa. Esses três tipos, por sua vez, poderiam apresentar diferentes formas de evolução, aguda ou crônica. Ressaltou, entretanto, a referida pesquisadora, que as formas catarrais poderiam apresentar evolução aguda ou crônica; as flegmonosas seriam sempre agudas e as apostematosas, crônicas. A forma catarral considerada incipiente ou resultante de uma infecção latente, que muitos consideraram uma variante subclínica, foi conceituada como sendo um distúrbio da secreção ou uma forma clínica de mastite, resultante de um processo inflamatório inespecífico.

WELBORN (1994) caracterizou as mastites segundo a etiologia do processo infeccioso da glândula mamária, definindo assim: mastite causada por coliformes (formas agudas e hiperagudas); mastite gangrenosa (causada por Staphylococcus aureus, Clostridium perfrigens e Pasteurella multocida ou P. haemolytica); caracterizou ainda, esse autor, uma forma de mastite contagiosa que poderia ser determinada por Streptococcus agalactiae, Streptococcus uberis ou Staphylococcus aureus. Observou-se, entretanto, a imperfeição do critério inicialmente proposto para essa classificação, pois a modalidade de mastite "gangrenosa" faz referência a uma manifestação clínica, bem caracterizada pela lesão anatomopatológica, mas essa mastite poderia ser determinada por um agente etiológico considerado causador das mastites "contagiosas". Essa condição de ser uma forma contagiosa de mastite relacioná-la-ia diretamente com a epidemiologia da doença, (pois os referidos germes são ubiqüitários) e não com as manifestações clínicas da doença.

Atualmente, o desenvolvimento de várias técnicas diagnósticas permitiu aos pesquisadores maior capacidade para isolar e identificar corretamente um grande número de bactérias, leveduras, algas e vírus, agentes etiológicos causadores das mastites. Todavia, a inexatidão no diagnóstico clínico dessas enfermidades da glândula mamária não se deveria atribuir apenas às deficiências tecnológicas e às metodologias do exame clínico, mas à precariedade de formação técnico-metodológica do pessoal responsável pela produção leiteira ou dos sistemas de ordenha. Tal conceito poderia também ser aplicado aos clínicos veterinários que não assimilaram e nem meditaram sobre os fatos observados nas pesquisas relatadas anteriormente, evidenciando, às vezes, claros equívocos lógico-formais, para a perfeita conceituação de sanidade da glândula mamária. 


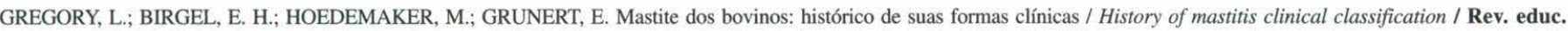
contin. CRMV-SP / Continuous Education Journal CRMV-SP, São Paulo, volume 4, fascículo 3, p. 31 - 38, 2001.

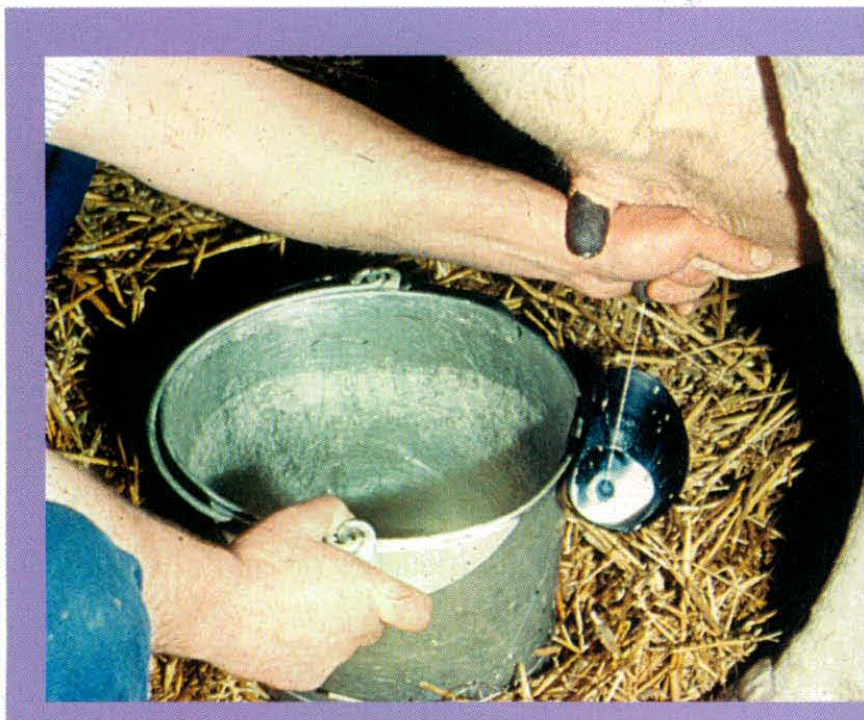

Figura 4. Inspeção do leite durante a ordenha, prova do fundo preto.

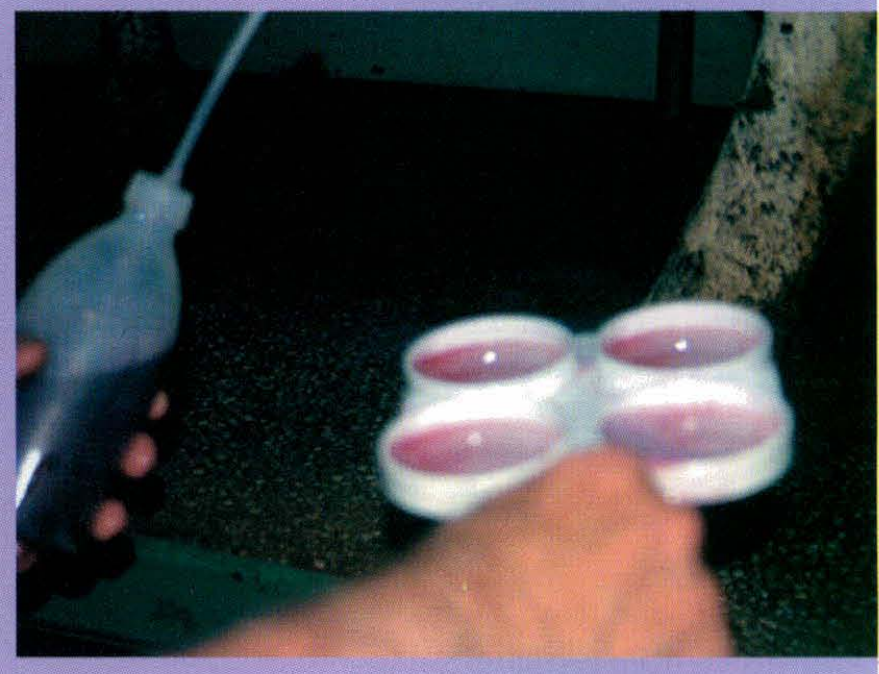

Figura 5. Exame do leite, prova do CMT.
WENDT et al. (1994) classificaram as mastites de acordo com a forma clínica e o agente etiológico que as poderiam causar. A avaliação histopatológica de sua casuística permitiu ao referido autor identificar cinco formas inespecíficas de mastites e cinco formas granulomatosas. Às formas, nas quais não foi possível estabelecer uma relação direta entre a ação do agente etiológico e os principais sintomas da mastite, o autor denominou-as de formas inespecíficas e recomendou que sua classificação obedecesse os critérios clínicos. Nesse grupo, figuraram: a mastite catarral aguda, a mastite catarral crônica, a mastite necrótico hemorrágica, a mastite apostematosa e a mastite intersticial não purulenta. As formas denominadas mastites granulomatosas foram aquelas que apresentavam relação direta e evidente entre a atuação do patógeno e as lesões, ou seja, uma relação direta entre a etiologia e o sintoma. Para esse estudo e classificação, WENDT et al. (1994) procederam ao isolamento e identificação do agente etiológico da mastite, bem como estabeleceram a caracterização histopatológica das lesões. A esse grupo de mastites granulomatosas, com processos infecciosos específicos, pertenceriam a mastite tuberculosa e outras causadas por micobactérias atípicas, pela Nocardia asteróides e pelas de origem micótica, bem como por aquelas acompanhadas por formação de abscessos. Neste caso, ressalte-se que o referido autor não obedeceu ao critério etiológico de classificação, como foi anteriormente mencionado, mas seguiram-se conceitos histopatológicos.

$\mathrm{Na}$ avaliação das classificações que se baseiam nas lesões histopatológicas, não haveria condição de conside- rá-las como um modelo para as classificações dessas enfermidades em formas clínicas para se fazer o diagnóstico clínico, pois, para tanto, dever-se-ia exigir que todos os animais examinados fossem submetidos a uma biopsia, fato muito invasivo, nos conceitos modernos da Semiologia.

WENDT et al. (1994), ainda no relatado estudo, afirmaram que as diferentes classificações das formas de mastite teriam mais um caráter meramente didático, contrapondo-se, assim, às opiniões de outros estudiosos do assunto, que consideraram ser a classificação a base para a elaboração de diagnósticos nosológicos e etiológicos exatos e precisos, quando possíveis e, dessa forma, poder-se-ia contribuir com recomendações de medidas terapêuticas e profiláticas adequadas para combater e controlar a doença.

No período de 1971-1987, a INTERNATIONAL DAIRY FEDERATION (Federação Internacional de Produtores de Leite) apresentou e recomendou uma definição das inflamações da glândula mamária baseada em dois conceitos: avaliação do número de células somáticas e isolamento de patógenos de amostras de leite. Esses conceitos são detalhados no Quadro 1.

Em 1987, na publicação "Animal Pharm-Bovine Mastitis", foram apresentados e avaliados os métodos de diagnóstico de mastites recomendados pela Federação Internacional de Produtores de Leite - IDF, considerando insatisfatórios os critérios anteriormente aceitos e recomendados e, até então, tidos como fundamentais para a perfeita definição e conceituação dos processos inflamatórios da glândula mamária. Tal desconsideração dos princípios definidores da inflamação da glândula mamária alicerçou-se em dois fatos: primeiro, os testes exis- 
GREGORY, L.; BIRGEL, E. H.; HOEDEMAKER, M.; GRUNERT, E. Mastite dos bovinos: histórico de suas formas clínicas / History of mastitis clinical classification / Rev. educ. contin. CRMV-SP / Continuous Education Journal CRMV-SP, São Paulo, volume 4, fascículo 3, p. 31 - 38, 2001.

Quadro 1. Conceitos para caracterização das inflamações da mama, segundo o IDF, 1971/1987.

\begin{tabular}{|c|c|c|}
\hline $\begin{array}{c}\text { Número de células } \\
\text { somáticas no leite }\end{array}$ & Resultado negativo & Resultado positivo \\
\hline Células $/ \mathrm{ml}$ & Leite normal & Infecção Latente \\
\hline$<500.000$ & Processo inflamatório inespecífico & Mastite \\
\hline
\end{tabular}

tentes e recomendados falhavam no isolamento e identificação das bactérias, agentes etiológicos determinantes das mastites; segundo, o número de células somáticas variavam de maneira significante, em diferentes condições fisiológicas.

Por isso, a referida Federação deu destaque às formas de mastites, inoportunamente designadas mastites subclínicas, afirmando, categoricamente: "A maioria das mastites são subclínicas e, muito embora as bactérias estejam presentes, as manifestações observadas na glândula mamária não são detectadas pelos pecuaristas; estas mastites, entretanto, reduzem o volume de leite produzido no quarto afetado e modificam a composição do leite". A partir de então difundiu-se, sem obediência aos princípios da Patologia Médica Veterinária e de Semiologia, o conceito de mastites subclínicas que, seguramente, não tem propiciado condições de diferenciar leites higienicamente produzidos daqueles oriundos de mamas acometidas por mastites. Recomendação de significativa importância para a pecuária leiteira seria a de avaliar se o conceito de mastite subclínica demonstrou eficiência para o controle das mastites, com reais benefícios ao exercício da clínica veterinária, ao bem estar animal ou à evolução do estudo da etiopatogenia das inflamações da glândula mamária.

Em resumo, finalmente, pode-se afirmar que, na evolução dos estudos relacionados à patogênese e etiologia das mastites, no último quarto do século XX, surgiram inúmeras classificações de mastites e que foram referidas em compêndios de Medicina Veterinária; algumas são verdadeiras reminiscências de outras referidas na evolução histórica do assunto, baseando-se em princípios anatomopatológicos, microbiológicos ou epidemiológicos e não, como seria de esperar, baseadas nos clássicos padrões da Propedêutica Médico Veterinária, que permitiriam, pelas manifestações clínicas (sinais e sintomas), presentes nas inflamações dos tecidos da mama, perfeita orientação diagnóstica e real condução da terapia indicada.
Estas foram as classificações definidas, pelos critérios a seguir detalhados:

1. Anatomopatológico - por lesões detectadas por exames histopatológicos, que não são de uso rotineiro em clínica, das doenças da glândula mamária, classificando-as em mastites parenquimatosas, intersticiais e mistas;

2. Microbiológico - segundo o isolamento do agente etiológico determinante das mastites, porém a especificidade e sensibilidade da metodologia é pequena, pois segundo o IDF os testes bacteriológicos freqüentemente falham no isolamento dos agentes etiológicos determinantes e o exame microbiológico do leite não é rotina generalizada na avaliação das condições da glândula mamária (SCHALM et al., 1971; INTERNATIONAL DAIRY FEDERATION, 1987);

3. Microbiológico/Epidemiológico, caracterizando mastites contagiosas e ambientais - a definição desses tipos de mastites dependeria do isolamento do agente etiológico e da real conceituação dos "habitats" desses agentes, pois freqüentemente eles são ubiqüitários (CULLOR et al., 1990);

4. Patogenicidade dos agentes etiológicos, caracterizando-os em patógenos maiores e menores - a definição dessas mastites exige, além do isolamento e identificação do agente etiológico, a necessidade de conceituar definitivamente o significado de patógeno maior ou menor e também de deixar claro se a avaliação seria, realmente, pela prevalência ou pela patogenicidade do agente patogênico (RADOSTITIS et al., 1994);

5. Pela evolução da doença - classificar-seiam as mastites em: superagudas, agudas, subagudas, crônicas e subclínicas. A perfeita caracterização da doença dependeria de duas condições fundamentais: identificação das manifestações clínicas e do momento da instalação da enfermidade, para, então, avaliar a evolução. 


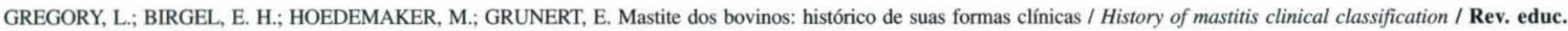
contin. CRMV-SP / Continuous Education Journal CRMV-SP, São Paulo, volume 4, fascículo 3, p. 31 - 38, 2001

Em conclusão, e avaliando o exercício da prática médico-veterinária no diagnóstico, tratamento e profilaxia das mastites, é razoável recomendar-se que essas doenças inflamatórias da glândula mamária, consideradas as manifestações clínicas, sejam classificadas em quatro formas:

1. Mastites catarrais, agudas ou crônicas (cerca de $78 \%$ da prevalência da doença no Brasil - caracterizadas por modificações do aspecto do leite, que apresenta grumos);

2. Mastites flegmonosas, sempre de evolução aguda (até $1 \%$ da prevalência, observada no Brasil) - caracterizada por intensa sintomatologia sistêmica e transformação do leite em secreção sero-sangüinolenta);

3. Mastites apostematosas, usualmente crônicas em suas evoluções (com até $22 \%$ da prevalência no Brasil) - caracterizada pela transformação do leite em secreção purulenta;

4. Distúrbio da secreção láctea - caracterizada por aumento da celularidade e/ou do $\mathrm{pH}$ do leite, representando casos de mastites que merecem elucidação posterior e avaliação da evolução do caso, representariam infecções latentes e/ou inflamações inespecíficas, causadas por retenção de leite, traumatismos da ordenha ou ocorrência em condições fisiológicas específicas. Nesses casos as vacas deveriam ficar em observação e serem submetidas à melhoria do manejo de ordenha e, em condições ideais, posteriormente, poderia ser estabelecido o diagnóstico definitivo.
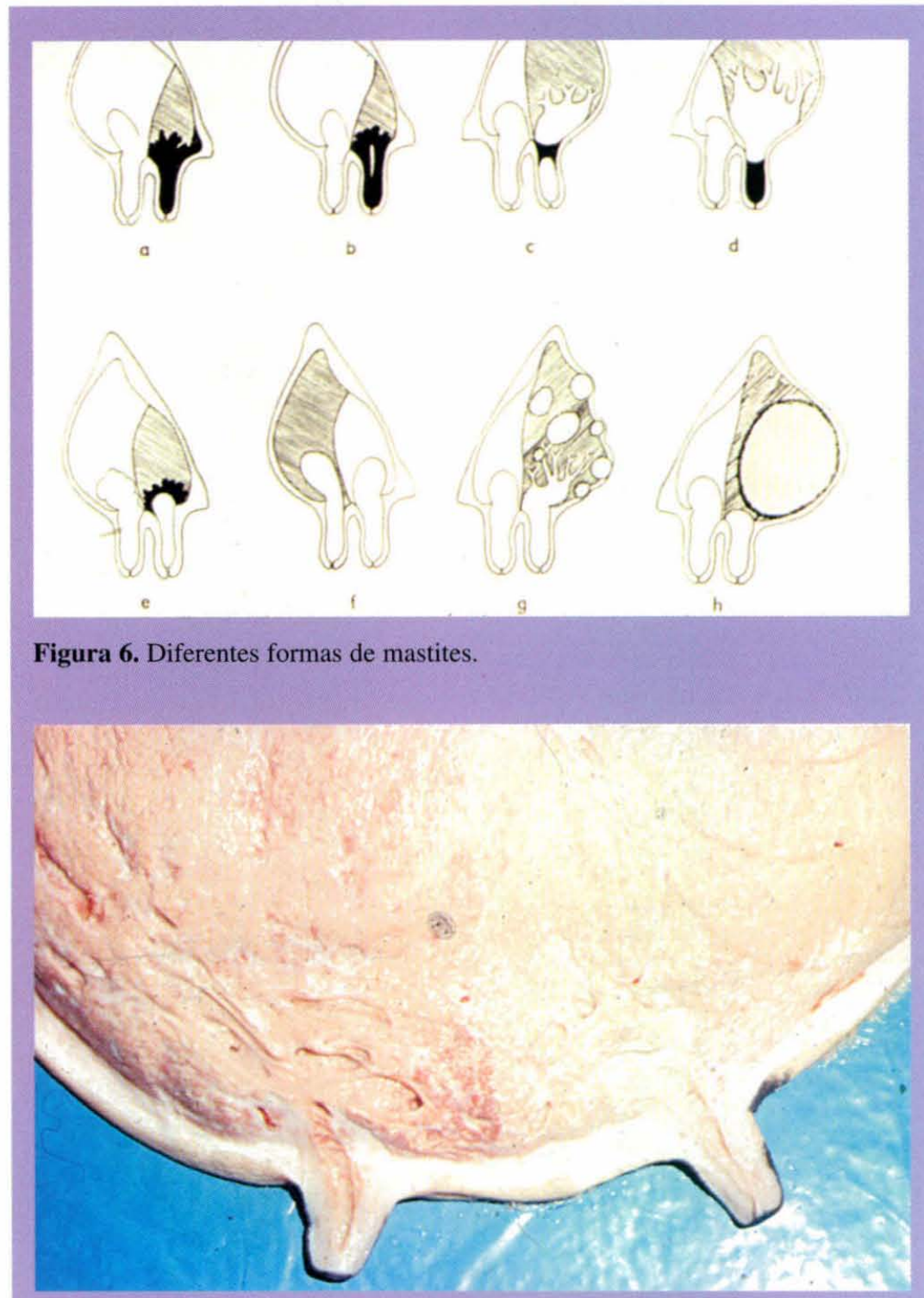

Figura 7. Parênquima de uma glândula mamária com mastite catarral.

\section{SUMMARY}

This review will expose an account of the history of mastitis ranging from the $18^{\text {th }}$ century until present. The bibliography was found in the library of the Tierärtzliche Hochschule (School of Veterinary Medicine) of Hannover, Germany.

Key words: mastitis, veterinary clinical practice, bovine. 
GREGORY, L.; BIRGEL, E. H.; HOEDEMAKER, M.; GRUNERT, E. Mastite dos bovinos: histórico de suas formas clínicas / History of mastitis clinical classification / Rev. educ. contin. CRMV-SP / Continuous Education Journal CRMV-SP, São Paulo, volume 4, fascículo 3, p. 31 - 38, 2001.

\section{REFERÊNCIAS}

1. CULLOR, J. S.; TYLER, J. W.; SMITH, B. P. Disorders of the mammary gland. In: SMITH, B. P. Large animal internal medicine. St. Louis: Mosby, 1990. p. 1044-1067.

2. ESCHERICH, E. Die Darmbakterien der Säuglinge. Stuttgart: Med. Hochsch, 1885.

3. GÖTZE, R. Zur klinischen Diagnostik und Behandlung der Kokkenerkrankungen des Euters. Berlin Tierärztichel Wochenschraft , v. 40, p. 649-656, 1931.

4. HAUBNER, G. C. Die inneren und äußeren Krankheiten der landwirthschaftlichen Haussäugetiere. 5. Aufl. Anclam: Dietze, 1867. p. 392-395.

5. HEINDRICH, H. J.; RENK, W. Krankheiten der Milchdrüse bei Haustieren. Berlin: Paul Parey, 1963.

6. HESS, E. Erkrankungen des Euters. Braumüller: Wien \& Leipzig, 1911. p. 25-192.

7. INTERNATIONAL DAIRY FEDERATION. Bovine Mastitis. In: Animal Pharma. Bruxelas: V \& O Publication, 1987. p. 1$52 ; 53$.

8. KITT, L.; GLAGE, F. Die Milchdrüsen. In: KITT, L. (Hrsg.): Ellenbergers Handbuch der vergleichenden Histologie und Physiologie der Haussäugetiere, Wien: von Moritz Perles. 1908. p. 337-394.

9. NOCARD, P.; MOLLEREAU, R. Sur la mammité contágieuse. Paris: Masson, 1885. p. 817-831.
10. POELS, R. Mastitis bei Rind, Schaf und Ziege, Tijdschr. Veeartsenijk., v. 37, p. 789-824, 1910.

11. RADOSTITIS, O. M.; BLOOD, D. C.; GAY, C. C. Veterinary medicine. 3. ed. Londres: Baillière Tindall, 1994. p. 563-627.

12. RYCHNER, R. Bujatrik (Stand und Fortgang der Tierheilkunde). Leipzig: Fischer, 1835. p. 293-318.

13. SCHALM, O. W.; JAIN, E. J.; JAIN, N. C. Bovine mastitis. Philadelphia: Lea \& Febiger, 1971.

14. Von FRANCK, L. Handbuch der Tierärztlichen Geburtshilfe. Berlin: Verlag Miegangt Hempel \& Paren, 1876. p. 549-566.

15. Von Willburg, A. K. Anleitung für das Landvolk in Absicht auf die Erkänntniß und Heilungsart der Krankheiten des Rindviehes, Nürnberg: Verlag Stein, 1787. p. $67-138$

16. WEIGT, U. Untersuchungen über die bovine Hefemastitis unter besonderer Berücksichtigung ihrer Entstehung. Hannover: Tierärztl. Hochschule, Habil.-Schr., 1973.

17. WELBORN, R. Zur Diagnose und Einteilung der Euterentzündungen, Deutsche Tierärztichel Wochenschraft, v. 65, p. 497$503,1994$.

18. WENDT, K.; BOSTEDT, H.; MIELKE, H.; FUCHS, A. W. Euter - und Gesäugekrankheiten. Stuttgart: Fischer, 1994. p. $226-431$
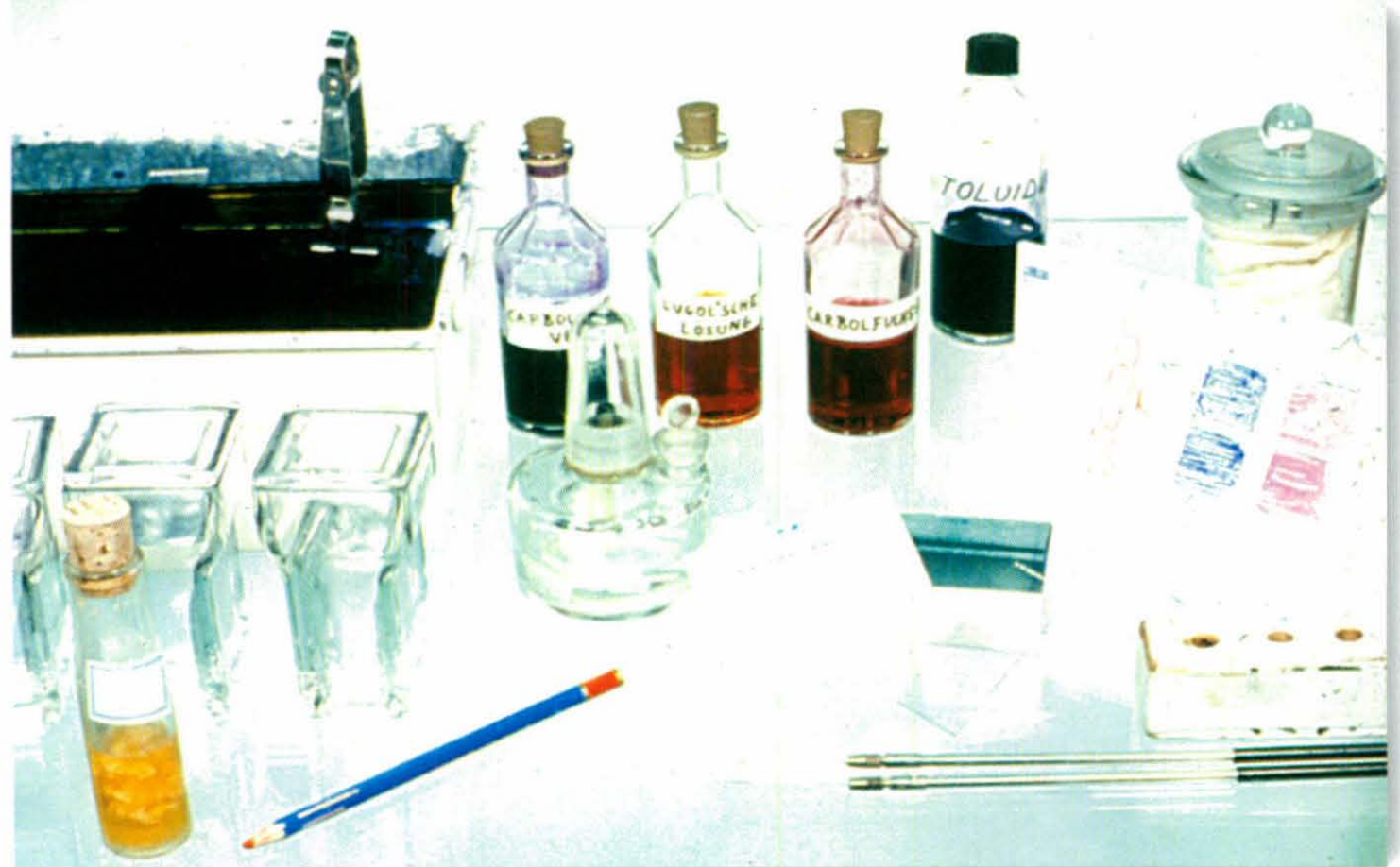